\title{
Remnant Gastric Perforation at a Patient With Colon Interposition: A Rare Case
}

\author{
Varlik Erol ${ }^{\mathrm{a}, \mathrm{b}}$, Levent Ugurlu ${ }^{\mathrm{a}}$, Mutlu Unver ${ }^{\mathrm{a}}$, Safak Ozturk ${ }^{\mathrm{a}}$, Gokhan Akbulut ${ }^{\mathrm{a}}$, Cengiz Aydin ${ }^{\mathrm{a}}$
}

\begin{abstract}
The purpose of performing surgical treatment after benign or maligned pathologies of the esophagus is to provide the continuity of the intestinal system. Especially after caustic esophagus injuries mostly colon interposition is performed to provide continuity. In this case study was made to determine actions to be taken for follow-up and as a treatment method for patients developing remnant perforation at the stomach after a colon interposition. A 53-year-old female patient came with complaint of abdominal pain for 2 days. Anamnesis showed that left colon interposition was performed because of esophagus stricture development after she drank caustic substance about 10 years ago. After acute abdominal findings during the physical examination, a direct abdominal graphy was made while standing and the X-ray of the lungs showed free air in the inner abdomen, together with findings of perforation at the computed tomography (CT), and it was decided to perform an urgent surgical intervention. During the exploration a perforation of approximately $1 \mathrm{~cm}$ was determined on the front side of the remnant gastric antrum. The perforation was sutured primarily with $2 / 0$ silk. Postoperative on the fourth day, the oral intake of the patient was opened which is tolerated and the patient was discharged on day 7 after surgery. If no results are obtained from the endoscopic dilatation methods performed on patients developing stricture after caustic esophagus and stomach injuries, the most appropriate method to provide the continuity of the intestinal system is a left colon interposition, which has got perfect long-term results. Although especially complications of the remnant organ are rarely seen, regarding cases with acute abdominal examination findings besides complications belonging to the colon graft, the remnant organ's pathologies must be kept in mind and exploration must be performed with caution.
\end{abstract}

Keywords: Colon interposition; Remnant gastric perforation; Treatment

Manuscript accepted for publication November 14, 2014

aDepartment of General Surgery, T.C.S.B. Tepecik Teaching and Research Hospital, Izmir, Turkey

${ }^{b}$ Corresponding Author: Varlik Erol, Department of General Surgery, T.C.S.B. Tepecik Teaching and Research Hospital, Yenisehir-Izmir, Turkey.

Email: varlikerol@gmail.com

doi: http://dx.doi.org/10.14740/jmc1998w

\section{Introduction}

The purpose of performing surgical treatment (organ interposition) after benign or maligned pathologies of the esophagus is to provide the continuity of the intestinal system. Colon is preferred, because functions are good and tolerable after surgical replacement treatments for this purpose. Isoperistaltic colon graft should be used for esophagus reconstructions, because anti-peristaltic reconstructions may appear together with distinct spasms [1]. Most frequent indications of a colon interposition are gastro-esophageal cancer, non-dilate esophagus narrowness developing related to reflux esophagitis, common narrowness related to chemical exposure, congenital esophagus atresia, achalasia and esophagus perforations where conservative treatment is unsuccessful. Especially after caustic esophagus injuries, mostly colon interposition is performed to provide continuity. While early postoperative complications are common, they develop because of transplant necrosis, leak, fistula and narrowness at the anastomosis. Late complications are rarely seen [2]. In this case the treatment of a patient developing remnant gastric perforation after colon interposition was presented.

\section{Case Report}

A 53-year-old female patient came with complaints of abdominal pain for 2 days. Anamnesis showed that left colon interposition was performed because of esophagus stricture development after she drank caustic substance about 10 years ago. After acute abdominal findings during the physical examination, a direct abdominal graphy was made while standing and the X-ray of the lungs showed free air in the inner abdomen, together with findings of perforation at the computed tomography $(\mathrm{CT})$, and it was decided to perform an urgent surgical intervention (Fig. 1, 2).

During the exploration after the laparotomy a perforation of approximately $1 \mathrm{~cm}$ was determined on the front side of the remnant gastric antrum. Gastric tissue was excised from the perforated area for pathologic inspection. The perforation was sutured primarily with $2 / 0$ silk. Postoperative on the fourth day the oral intake of the patient was opened, and the patient was discharged on day 7 after surgery. The gastric biopsy of 


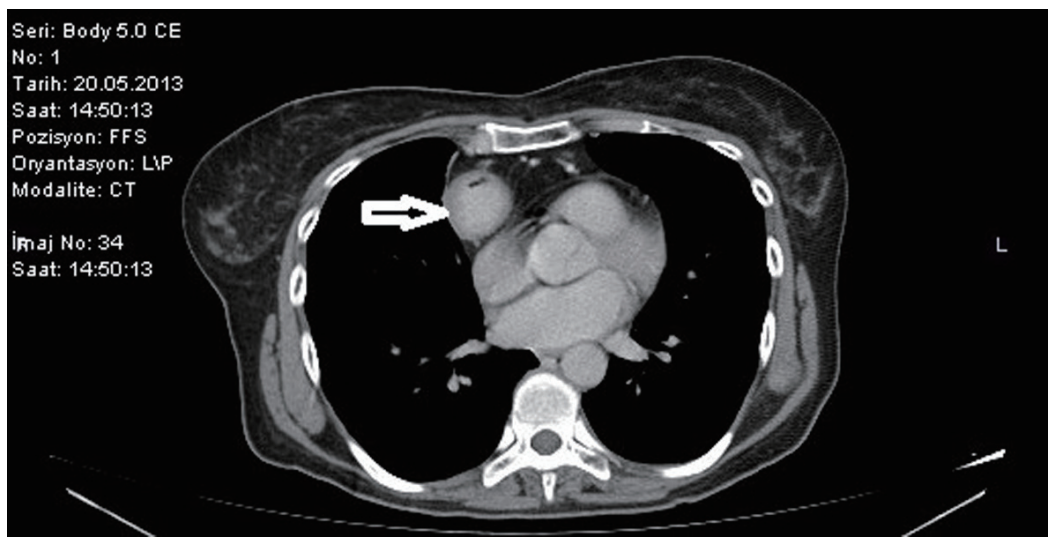

Figure 1. CT image of colon graft.

the patient was reported as benign inflammatory gastric tissue. Within the time after discharge, control abdominal tomography and tumor indicators, with the purpose of screening the remnant stomach, stated no pathology.

\section{Discussion}

Esophageal and gastric injuries due to caustic substance exposure occur mostly because of substances containing alkaline and acid. The most important factors that designate the patient's degree are the density of the caustic agent and the time span of the contact. Depending on the patient's degree after exposure, retrostemal and/or abdominal pain, hematemesis, harm of the upper respiratory tract, esophagus and/or stomach perforation, mediastinitis and esophagus narrowness may develop. Approximately $10-30 \%$ of patients happen to have esophagus narrowness after a caustic injury [3]. If no results are obtained from the endoscopic dilatation methods performed on patients developing stricture after caustic esophagus and stomach injuries, the most appropriate method to provide the continuity of the intestinal system is a left colon interposition which has got perfect long-term results. The colon, as well as the stomach, is accepted as a good organ based on function and endurance to be used instead of the esophagus. The first use of the colon replacing the esophagus was described by Kelling and Vuillet about 100 years ago $[4,5]$. With the purpose of esophagus replacement, right colon, left colon and transverse colon can be used as a graft. However, clinical trials support that left colon interposition is superior $[6,7]$. With this technique the whole colon is mobilized widely, middle colic artery is tied; the colon is resected at any point according to the patient's anatomy between the left flexura and the descendent colon [6]. However, complications like anastomosis leak, narrowness at the pharyngeal anastomosis, necrosis at the remnant esophagus and gastric cancer may rarely develop after this treatment. Also it is reported that on a long term, as a result of the irritation of the colonic mucosa by stomach acid content or the bile juice, cancer developed at the used colon graft [8]. It is not proven that there is a higher esophagus cancer risk after a colon interposition and the residue esophagus resection is still debateable. However, based on a high complication risk, esophagus resection is not performed [9].

When searched through literature, it is not determined that a remnant gastric perforation as a complication occurs after a colon interposition for a long term. When acute abdominal findings develop in a long term at patients with colon interposition, complications like colonic, necrosis at the graft and

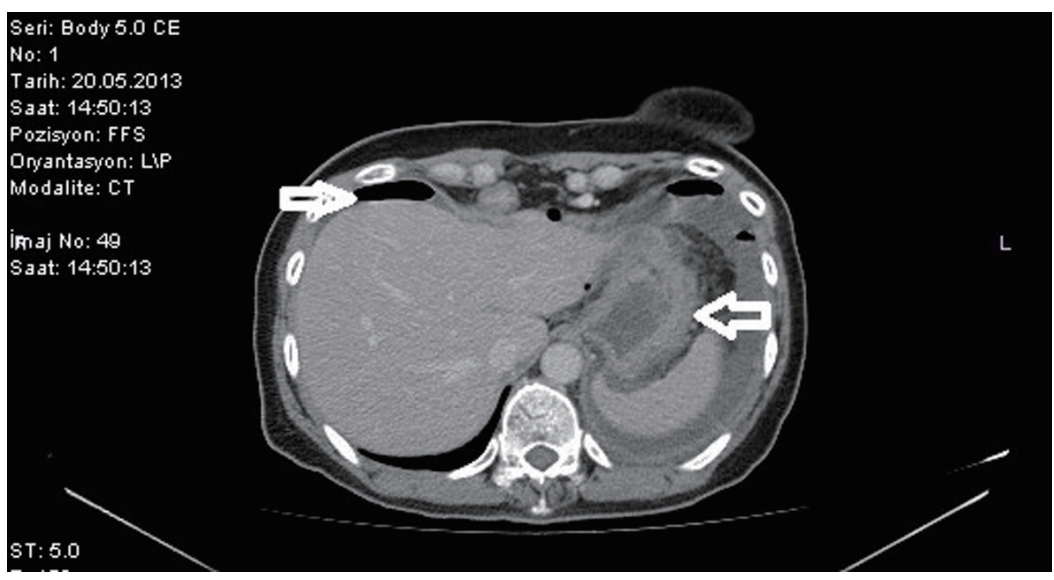

Figure 2. CT image of the remnant stomach and the free air below the diaphragm. 
perforation probability must be kept in mind, and the exploration must be made very carefully in order to avoid harm to the colonic graft during the exploration. Together with the abdominal component of the colonic graft, all abdominal inner empty organs must be explored carefully during operation. In the presence of remnant gastric perforation the defect must be repaired primarily by avoiding stomach resection if possible. As it is not possible to pursue and decompress with a nasogastric catheter within the postoperative period, the patient must be clinically monitored attentively. As it is not possible to perform endoscopic control of the residue esophagus and the stomach, CT and magnetic resonance screening will be useful for the pursuit.

\section{Conclusion}

Although colon interposition has perfect long-term results in providing continuity to the intestinal system after benign and malign pathologies of the esophagus, it may cause complications with high morbidity and mortality like graft fibrostenosis, ulceration at the colon segment, gastrological reflux, colo-pericardial and colo-bronchial fistula, cancer at the colon graft and perforation. Although especially complications of the remnant organ are rarely seen, regarding cases with acute abdominal examination findings besides complications belonging to the colon graft, the remnant organ's pathologies must be kept in mind and exploration must be performed with caution.

\section{Conflict of Interest}

The authors declare that there is no conflict of interests regard- ing the publication of this paper.

\section{References}

1. Rice TW. Colon replacement. In: Pearson FG, Deslauriers J, Ginsberg RJ, et al, eds. Esophageal surgery. New York: Churchill Livingstone; 1995:761-774.

2. Spitali C, De Vogelaere K, Delvaux G. Dysphagia after colon interposition graft for esophageal carcinoma. Case Rep Pathol. 2012;2012:738205.

3. Schaffer SB, Hebert AF. Caustic ingestion. J La State Med Soc. 2000;152(12):590-596.

4. Kelling GE. Oesophagoplastik mit Hilfe des Querkolons. Zentralbl Chir. 1911;38:1209-1212.

5. Vuillet H. De l'oesophagoplastie et des diverses modifications. Semin Med. 1911;31:529-534.

6. DeMeester TR, Johansson KE, Franze I, Eypasch E, Lu CT, McGill JE, Zaninotto G. Indications, surgical technique, and long-term functional results of colon interposition or bypass. Ann Surg. 1988;208(4):460-474.

7. Peters JH, Kronson JW, Katz M, DeMeester TR. Arterial anatomic considerations in colon interposition for esophageal replacement. Arch Surg. 1995;130(8):858-862; discussion 862-853.

8. Kuwabara Y, Kimura M, Mitsui A, Ishiguro H, Tomoda $\mathrm{K}$, Mori Y, Ogawa R, et al. Adenocarcinoma arising in a colonic interposition following a total gastrectomy: report of a case. Surg Today. 2009;39(9):800-802.

9. Han Y, Cheng QS, Li XF, Wang XP. Surgical management of esophageal strictures after caustic burns: a 30 years of experience. World J Gastroenterol. 2004;10(19):28462849. 